\title{
Developing new heat pump system to improve indoor living space in senior long-term care house
}

\author{
Chao-Hung Lu', Ming-Cheng Liao ${ }^{2}$, Wen-Chin Lin ${ }^{3}$, Wen-Pei Sung ${ }^{4}$ \\ ${ }^{1}$ Department of Civil Engineering, Chung Hua University, Hsinchu, 30012, Taiwan, R.O.C. \\ ${ }^{2,4}$ Department of Landscape Architecture, National Chin-Yi University of Technology, \\ Taichung, 41170, Taiwan, R.O.C. \\ ${ }^{3}$ Department of Architecture and Urban Planning, Chung Hua University, Hsinchu 30012, Taiwan, R.O.C. \\ ${ }^{4}$ Corresponding author

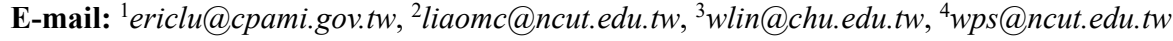

Received 24 February 2019; received in revised form 22 June 2019; accepted 29 June 2019

DOI https://doi.org/10.21595/jme.2019.20602

Check for updates

Copyright $(\mathbb{C} 2019$ Chao-Hung Lu, et al. This is an open access article distributed under the Creative Commons Attribution License, which permits unrestricted use, distribution, and reproduction in any medium, provided the original work is properly cited.

\begin{abstract}
The issue of an aging population is becoming increasingly acute in Taiwan; in 2018, seniors comprised over $14 \%$ of the total population. The quality of care for senior citizens hinges on the ability of long-term care facilities to create comfortable living spaces while ensuring energy efficiency by reducing electricity consumption, thereby providing them with an environment for aging in an active and positive way. This study proposes a new heat pump system that offers a cold source in the summer and a heat source in the winter. In addition, the air-conditioning and ventilation rates required for comfort in indoor living spaces are established to ensure the high quality of the care spaces in these types of institutions. The results after installation of the heat pump system were as follows: (1) Performance of the heat pump system: the inlet temperature of the heat pump chilled water was maintained at $7-10{ }^{\circ} \mathrm{C}$, and the outlet temperature, at $42-54{ }^{\circ} \mathrm{C}$. (2) Energy efficiency: Based on a $95 \%$ confidence interval, the average annual electricity consumption was $32.65 \mathrm{kwh} /$ day, which was $32.65 \%$ of the prior consumption level; the reduction of $67.35 \%$ is comparable to those of most heat pump systems. (3) Improvement of the indoor environment: In the hottest scenario, the indoor temperature was reduced by $3^{\circ} \mathrm{C}$ and the relative humidity to $55-65 \%$, which fall within comfortable ranges. After the heat pump system was introduced, significant improvements in ventilation, air quality and comfort were noted, as well as significant improvement in average total satisfaction scores. All improvements reached statistical significance. The overall objective of the system is to enhance the environmental quality in long-term senior care facilities and make them healthier and more energy efficient.
\end{abstract}

Keywords: long-term care space for seniors, heat pump system, indoor thermal comfort, indoor air quality.

\section{Introduction}

According to the "Long-term Care 2.0 Ten-Year Plan" [1] approved by the government of Taiwan in December 2016, Taiwan became an "aging society", as defined by the World Health Organization [2, 3], in 1993, when $7.1 \%$ of its population was aged 65 or more. Moreover, the government of Taiwan [1] estimated that Taiwan would officially become an "aged society" in 2018 , with a senior population of $14.5 \%$, and a "hyper-aged society" in 2026 , with $20.6 \%$ of the population being seniors. A further increase to $38.9 \%$ by 2061 was also projected. Along with the rapid rise in the senior population, the incidence rates of chronic diseases and functional disorders will also see drastic increases. In particular, the climate in Taiwan features high temperatures and high humidity in the summer and northeasterly monsoon and continental cold fronts in the winter, which impact the indoor environmental comfort of senior welfare and long-term care facilities. It is necessary to build a comfortable, healthy and energy-efficient living space for seniors according to their user characteristics.

Most people spend $90 \%$ of their lives indoors. The comfort of the indoor environment affects both human comfort and physical health, especially for seniors and those requiring special care 
[4-8]. The proposed new system in this study mainly combines the condenser of an air conditioning system and a heat pump system. The heat pump system absorbs heat from the air and the heat emitted by the condenser. This heat is stored in the form of hot water, and the cold after heat transfer is stored in cold water instead of discharged into the atmosphere so as not to cause energy waste. This new heat pump system and components provide a cold source in the summer and heat source in the winter. The cold and heat sources provide the required air-conditioning and ventilation rates to create a high-quality and energy-efficient living space, ensuring a stable, comfortable and healthy quality of care for seniors under institutional care.

A traditional air-conditioning system [9-13] operates by dissipating heat outdoors via a condenser to cool the indoor environment and improves the indoor air quality through outside air exchange. However, this heat exchange process results in wasted energy, and the heat dissipated into the atmosphere cannot be recycled or reused. A heat pump system [14-20], on the other hand, extracts heat from the air for heating and stores the energy in the form of hot water. The resulting cold source after heat transmission is discharged into the atmosphere, also resulting in wasted energy. Heat pump systems can be classified into four categories based on the type of heat source: air, water, geothermal and solar radiation. The air type extracts heat from the air to heat water; the water type extracts heat from groundwater, rivers, spring water, industrial wastewater, returned water from an air-conditioning system or cooling water. The geothermal type extracts heat from a geothermal source inside the earth. The solar radiation type collects solar energy via solar panels, or an evaporator for condensation in the heat pump compressor or thermosyphon heat exchanger, and stores the heat inside a hot water tank. If the solar panels or evaporator are cooler than the atmosphere, atmospheric heat may be absorbed in addition to solar radiation heat. This study combines the advantages of the air-conditioning system and the heat pump system to develop a new heat pump system. The heat pump system is connected with the condenser of a traditional air-conditioning system to develop this new proposed system, which absorbs heat from the condenser and air for storage in hot water. After the heat transfer produces the cold source, it is stored in cold water. The cold source is used in the summer and the heat source in the winter for air-conditioning and heating respectively to improve the temperature and humidity inside the care space while achieving energy efficiency. In addition, in-situ experiments were conducted to validate the optimal air-conditioning and ventilation rates inside the living space with a view to enhancing the health and quality of the care space.

\section{The proposed new heat pump system}

This system utilizes a fixed-temperature device for the heat pump system. Water is heated only when its temperature falls below a pre-set value. The hot water and cold water produced during the heating process are conveyed to their respective sinks. The hot water is used for showers and bathrooms, and as a heat source for winter heating; the cold water is used as a cold source for air-conditioning. This approach yields savings compared to the energy consumed to operate traditional equipment while overcoming the limit of only one type of use for each system. The new heat pump system is illustrated in Fig. 1. Basically, the system extracts heat from air, produces hot water and cold water through the heating process, stores each separately, and provides cold and hot vapor through the system. The heat is then transferred to cold water via a heat exchanger, which then restores the high-temperature and high-pressure refrigerant to the low-temperature and low-pressure states. The cycle repeats and, in the process, turns cold water into hot water. The system developed in this study, however, introduces low-temperature and low-pressure refrigerant into air-conditioners to provide cool air in the summer, and it provides hot water as a heat source for air-conditioners to provide warm air in the winter.

\subsection{Basic mathematical model of heat pump system and system testing}

The heat pump works by absorbing hot air from the environment to heat water, and cold air 
produced during the heating is discharged. The refrigerant starts at a cold temperature; the evaporator absorbs heat from the air and raises the temperature of the refrigerant, which is then compressed by the compressor and turned into high-temperature, high-pressure refrigerant. The heat is then transmitted to cold water through the heat exchanger, thereby heating the cold water. Once the high-temperature, high-pressure refrigerant transmits the heat to cold water, it is restored to the low-temperature and low-pressure states. This cycle of heating cold water into hot water repeats. Thus, when the outside temperature is higher, the water is heated faster and the heat pump is more energy-efficient. Actually, it is difficult to describe all the changes in the heat pump. Therefore, in this study, simplified equations [20] are used to describe the heat exchanges in the heat pump.

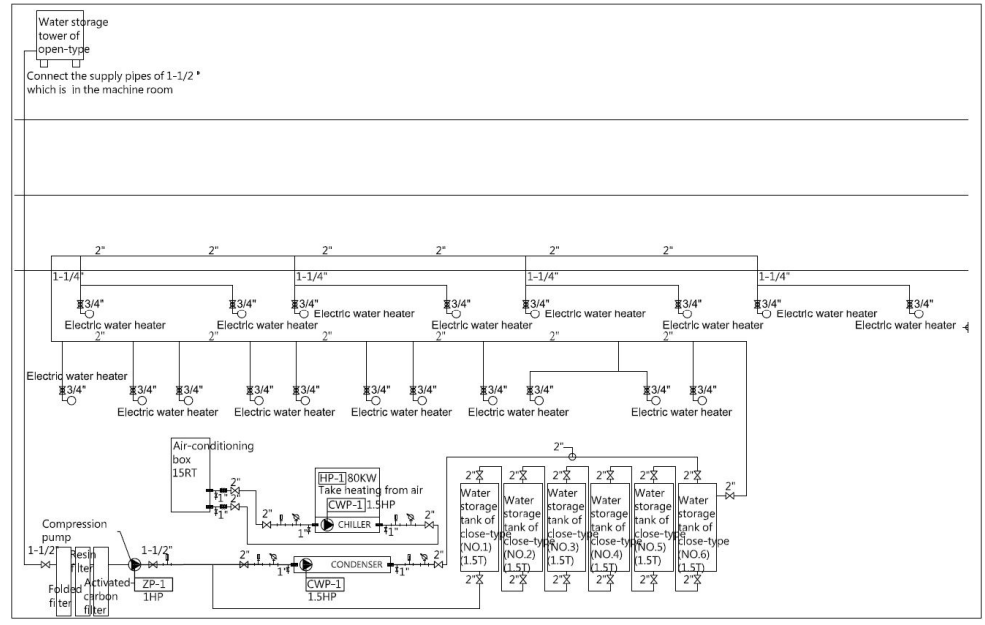

Fig. 1. Diagram of the proposed heat pump system

The energy of refrigerant entering into an evaporator can be expressed as follows:

$Q_{e v}=q_{r e f} \cdot s_{e v} \cdot T_{e v}(W)$,

where $q_{r e f}$ is the mass flow of the refrigerant entering into an evaporator; $s_{e v}$ is the entropy of the refrigerant behind the expansion valve; $T_{e v}$ is the temperature of the refrigerant behind the expansion valve.

The heat flow received from the environment through the evaporator can be shown as follows:

$Q_{\text {evapor }}=q_{\text {air }} \cdot c_{a} \cdot\left(T_{1}-T_{2}\right)(W)$,

where $q_{a i r}$ is the mass flow of the air entering into an evaporator; $c_{a}$ is the specific heat capacity of the air; $T_{1}, T_{2}$ are the input and output temperatures of the air, respectively.

Thermal power delivered by the compressor into a refrigerant can be expressed as follows:

$Q_{\text {comp }}=q_{\text {ref }} \cdot\left(s_{c}-s_{\text {evap }}\right) \cdot\left(T_{c}-T_{\text {evap }}\right)(W)$,

where $s_{c}$ is the entropy of the refrigerant behind the compressor; $s_{\text {evap }}$ is the entropy of the refrigerant behind the evaporator; $T_{c}$ is the temperature of the refrigerant behind the compressor; $T_{\text {evap }}$ is the temperature of the refrigerant behind the evaporator.

The energy input of the refrigerant into the expansion valve can expressed as follows:

$Q_{\text {cond }}=q_{\text {ref }} \cdot s_{c o} \cdot T_{c o}(W)$, 
where $S_{c o}$ is the entropy of the refrigerant behind the condenser; $T_{c o}$ is the temperature of the refrigerant behind the condenser.

To validate the ability of the heat pump proposed herein to produce heat and cold, the actual performance of the proposed system was tested. Fig. 2 shows that after the equipment absorbs heat from the air, the hot water produced reaches $60^{\circ} \mathrm{C}$, and the cold water, $5^{\circ} \mathrm{C}$. The temperature of this cold water is sufficient for application as a cold source for a chiller.

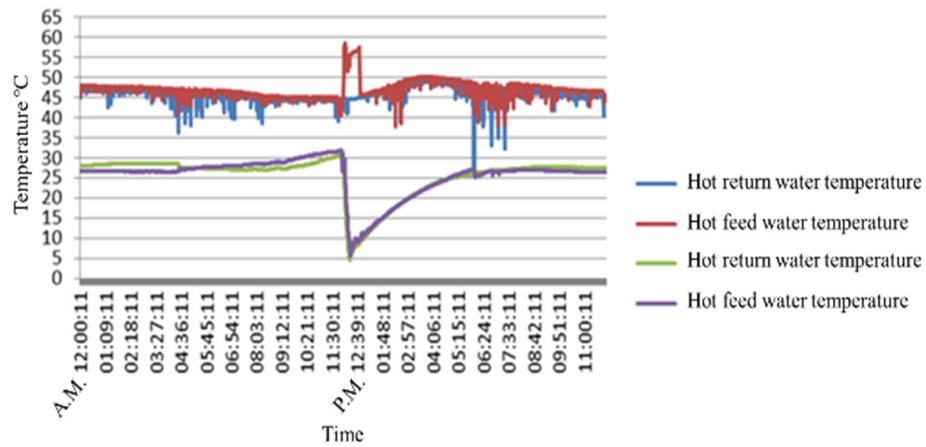

Fig. 2. MOHW Central Taiwan Seniors Home after improvement: trend chart of inlet and discharge water temperature of the heat pump

\subsection{Initial test results of the indoor environment}

This study utilized a heat pump system installed indoors to absorb hot vapor and improve the indoor humidity and temperature. The weather at the time of the experiment was a typical summer day in Taiwan, and the measurements are shown in Fig. 3.

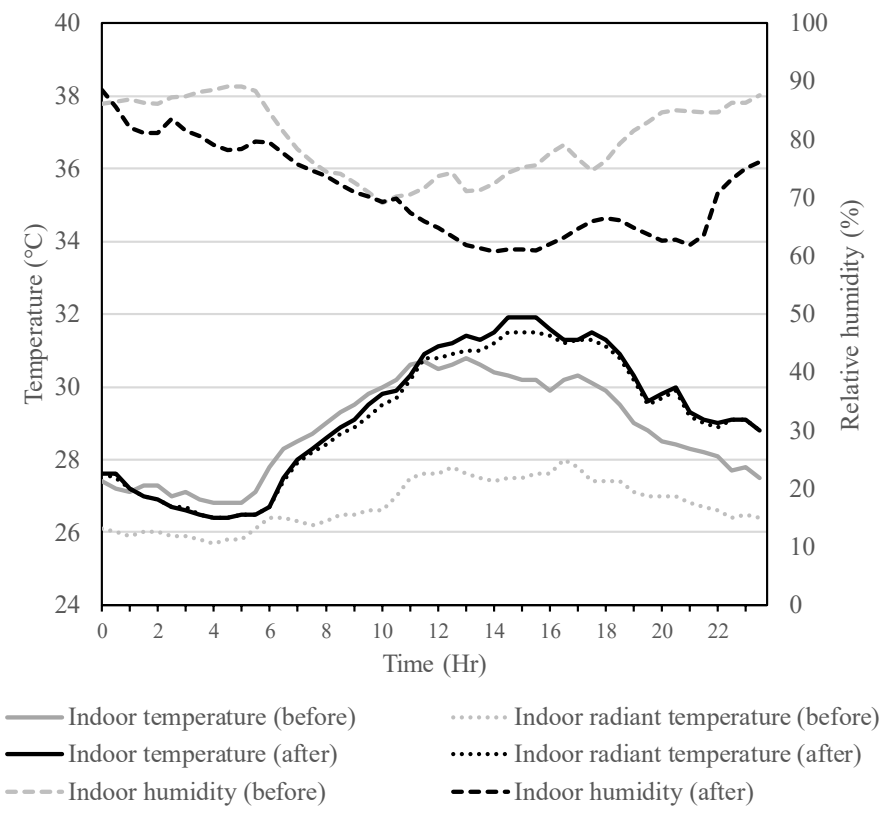

Fig. 3. The indoor thermal environment after improvement

Time-lapse data from the experiment showed that the indoor temperature was reduced by $3{ }^{\circ} \mathrm{C}$ in the hottest case, putting it within the comfortable temperature range; likewise, relative humidity was reduced to the comfortable range of $55-65 \%$. Under relative humidity, the temperature 
perceived by the human body differs from the actual ambient temperature. High temperature and high humidity hinder sweat evaporation and interrupt the body's heat balance mechanism, causing one to feel stuffy and uncomfortable. This condition becomes more and more apparent as the temperature rises. Relative humidity of 40-60 \% feels comfortable. As the relative humidity rises, one begins to feel warmer and warmer. The results of this experiment showed that the heat pump system indeed improved the indoor environment.

\section{Validation via long-term experiment: instruments and monitored items}

To learn about the actual benefits of the proposed new heat pump system, a remote monitoring system was established. This study aimed to examine how to ensure that heat pump systems, which are extensively used in these facilities, can be used to create both high-quality and energy-efficient environments so as to offer the senior occupants a stable quality of care, comfort and health. By providing cooling in the summer and heating in the winter, a well-run heat pump system can help ensure comfortable heating, air-conditioning and ventilation in indoor living spaces.

To monitor the outdoor environment, a small outdoor weather station, surface thermometers, and data recorders were used to collect data such as outdoor weather data and parameters, along with the temperatures of the building walls and ground surfaces. The monitored items included the following: 1. temperature, 2. relative humidity, 3. wind direction, 4. wind velocity, 5. atmospheric pressure, 6. black ball temperature, 7. solar radiation, 8. surface temperature of indoor concrete walls, 9 . surface temperature of outdoor concrete ground, 10 . surface temperature of outdoor concrete walls, and 11. surface temperature of outdoor lawn.

Indoor comfort monitoring instruments were used to observe the indoor thermal environment. The monitored items included the following: 1. temperature, 2. black ball temperature, 3. relative humidity, 4. wind velocity, 5. wind volume, 6. PMV (Predicted Mean Vote) value, and 7. PPD (Predicted Percentage of Dissatisfied) value.

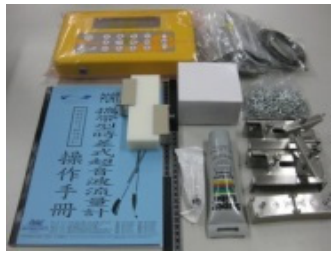

a) Ultrasonic flow meter

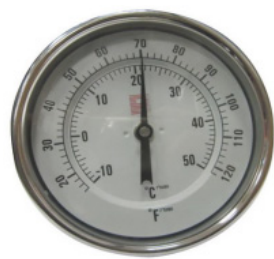

d) Thermometer for measuring the temperature in MEP lines

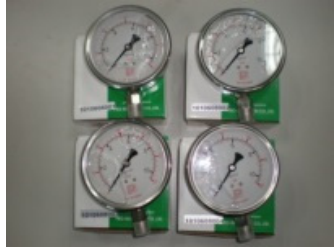

b) Pressure gauge for measuring the pressure in MEP lines

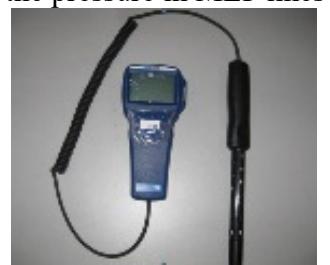

e) Temperature, humidity and $\mathrm{CO} 2$ concentration sensor

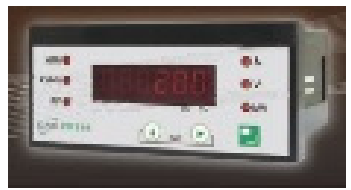

c) Multifunctional electric meter

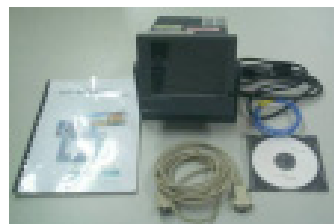

f) VR18 paperless recorder

Fig. 4. TAB measuring instruments for monitoring the heat pump system

The heat pump equipment was monitored remotely. The monitored items included three categories:

1. Heat pump hot water system: the heat pump COP (coefficient of performance), heat pump loading, heat pump inlet cold water temperature, heat pump outlet hot water temperature, heat pump inlet hot water temperature, pressure pump outlet water temperature, water tank inlet water temperature, water tank outlet water temperature, flow rate of heat pump hot water, flow rate of pressure pump outlet water, and flow rate of heat pump cold water; 2 . Electric meter for the heat 
pump: average voltage, average electrical current, electricity demand, power factors, and electricity used; and 3. Electric meter for air-conditioning: average voltage, average electrical current, electricity demand, power factors, and electricity used. The measuring instruments for the Test, Adjust and Balance, or TAB, of this proposed system are shown in Fig. 4. Fig. 5 shows the overall system built for this study. All the data were collected in real time and therefore provided true insights into the system's performance.

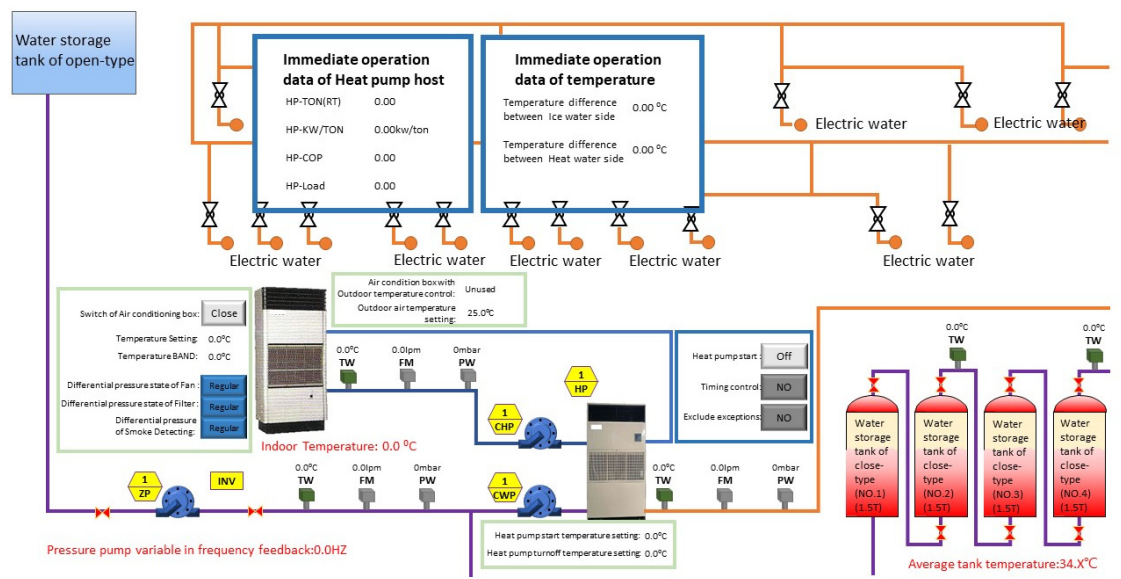

Fig. 5. The heat pump system at the Central Region Senior Citizens' Home

\section{Results and discussion}

\subsection{Operating conditions of the heat pump system}

Observation over an entire year showed that the inlet temperature of the heat pump cold water was maintained at around $7-10{ }^{\circ} \mathrm{C}$, while the outlet hot water temperature was maintained at around $42-54{ }^{\circ} \mathrm{C}$, as shown in Fig. 6 . With regard to energy efficiency, the home had previously used 20 units of electric hot water heaters, consuming around $100 \mathrm{kWh} /$ day.

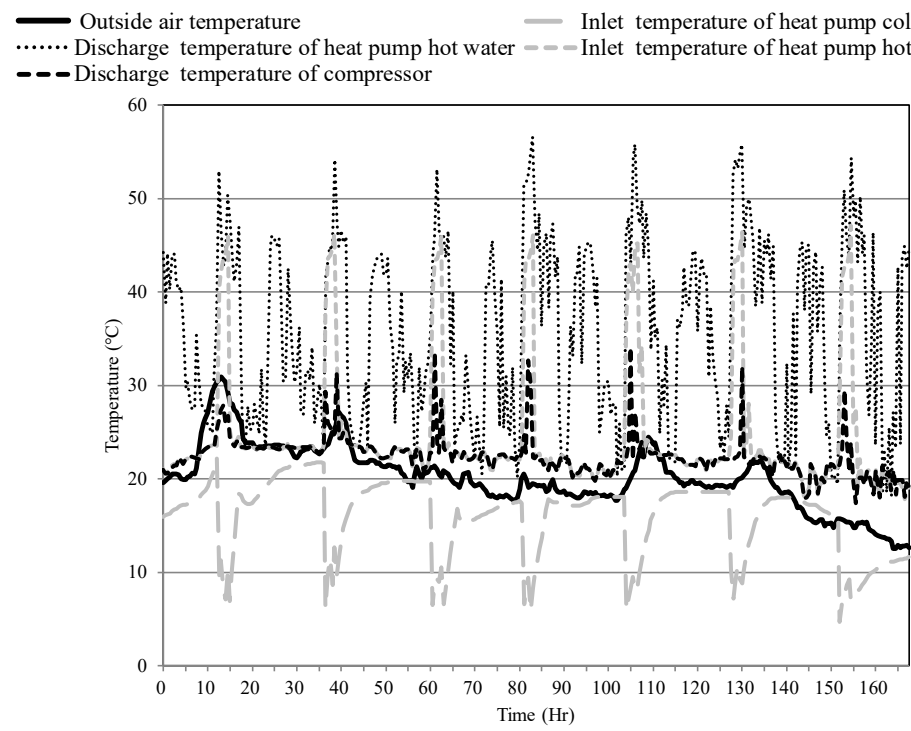

a) Spring 
DEVELOPING NEW HEAT PUMP SYSTEM TO IMPROVE INDOOR LIVING SPACE IN SENIOR LONG-TERM CARE HOUSE. Chao-Hung Lu, Ming-Cheng LiaO, Wen-Chin Lin, Wen-Pei Sung

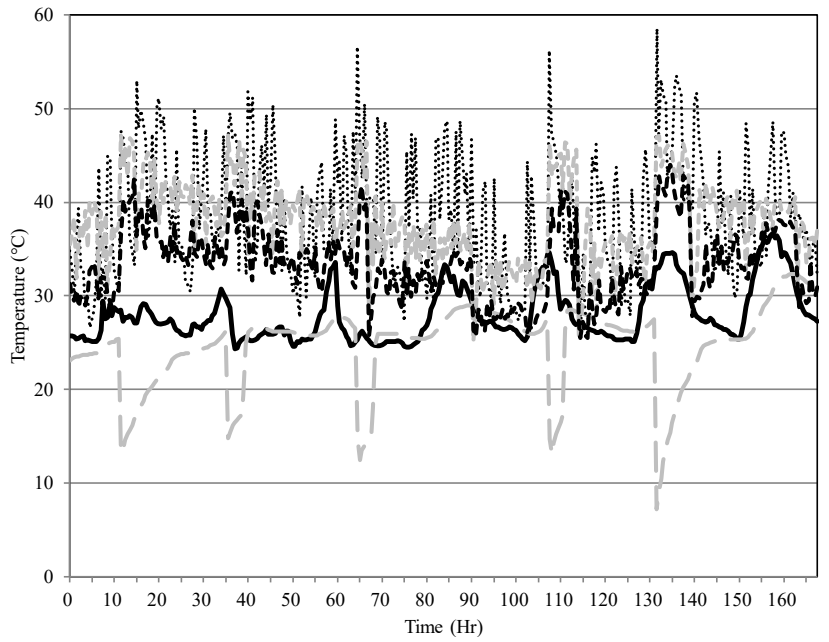

b) Summer

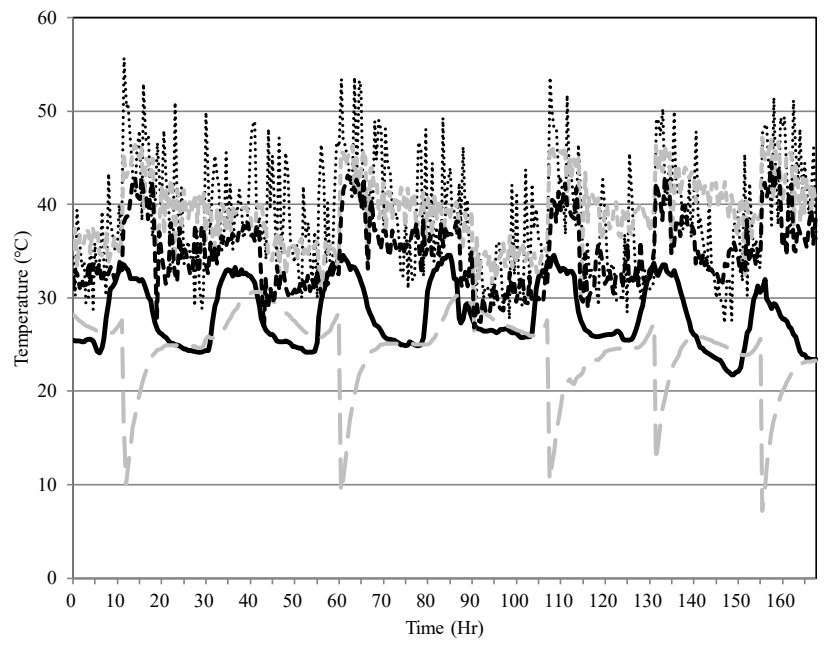

c) Fall

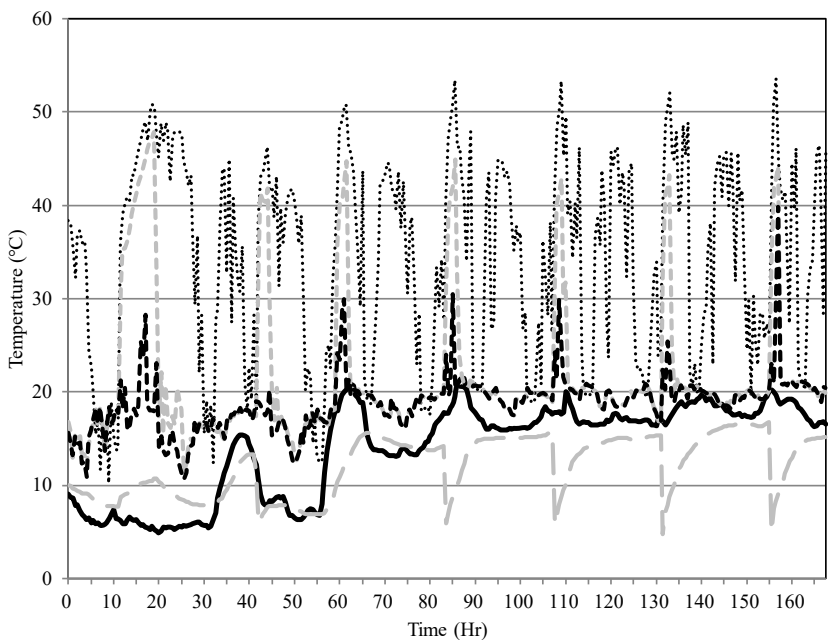

d) Winter

Fig. 6. Temperature of inlet/discharge water of the heat pump system: four seasons 
The electricity consumption of this proposed system is shown in Fig. 7. After the installation of the heat pump system, the average electricity used per day was $32.65 \%$ of the previous amount, discounting periods in which the system was not running or was running abnormally and based on a $95 \%$ confidence interval. In other words, there was energy saving of $67.35 \%$, supporting the initial assessment of excellent energy conservation.

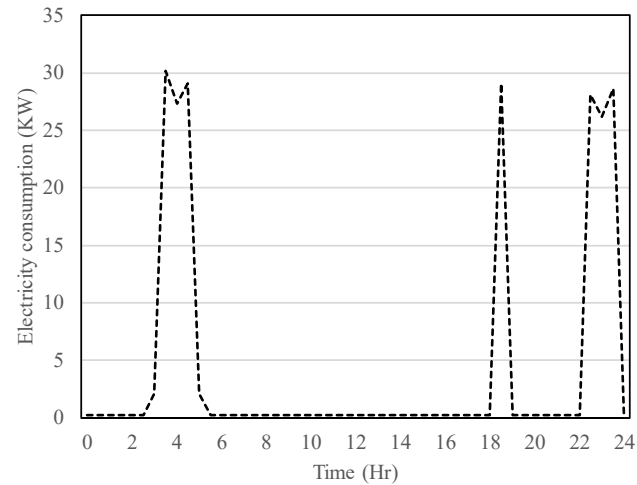

Fig. 7. Trend graph of the heat pump electricity consumption

\subsection{Thermal environment measurements inside the cafeteria}

The monitoring of the indoor thermal environment was divided into two stages. In the first stage, the indoor thermal environment of the cafeteria was measured to examine the relationship between thermal comfort and spatial distribution. Indoor thermal measurements of the personal living spaces were added in the second stage. The air-conditioning system was designed based on the requirements of the personal living spaces, and some mechanical, electrical and plumbing (MEP) lines and equipment were modified to suit the needs of the study. A comparison of the two stages revealed the impacts of varying user behavior, duration of use, number of users, and status of users on the requirements and functioning of the heat pump system.

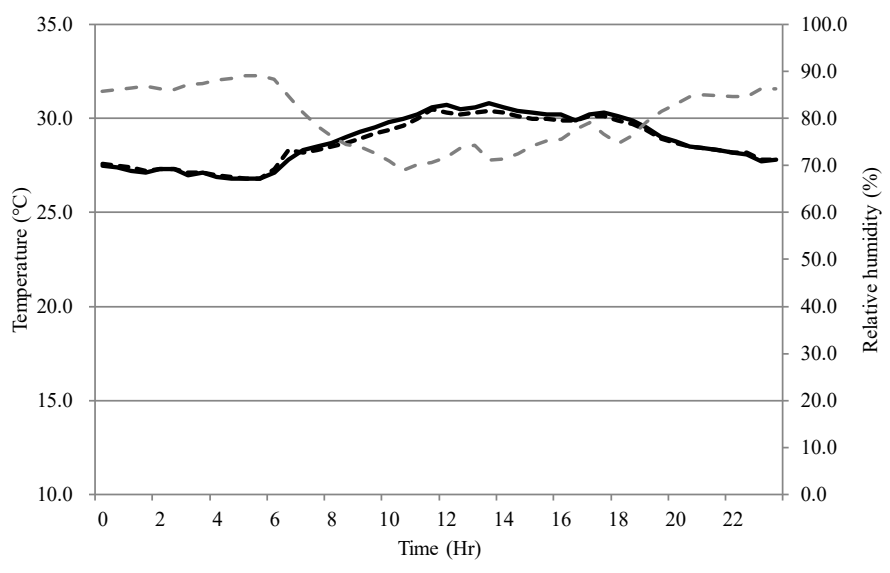

Fig. 8. Temperature and relative humidity in the cafeteria before improvement

Figs. 8 and 9 show changes in the indoor temperature and humidity before and after, respectively, the proposed system was installed in the public dining space. The data collected over time in the above experiments showed a drop of $3{ }^{\circ} \mathrm{C}$ in temperature and a reduction to $55-65 \%$ in relative humidity, which are sufficient for comfort. Under different relative humidity levels, the 
temperature perceived by humans varies from the actual ambient temperature. High temperature and high humidity affect sweat evaporation and compromise thermal balance in the human body, causing people to feel hot. This feeling becomes more and more apparent as the temperature rises. Relative humidity of 40-60 \% feels comfortable; with higher relative humidity, the air feels hotter. The results confirmed that the heat pump system can help improve the comfort of the indoor environment.

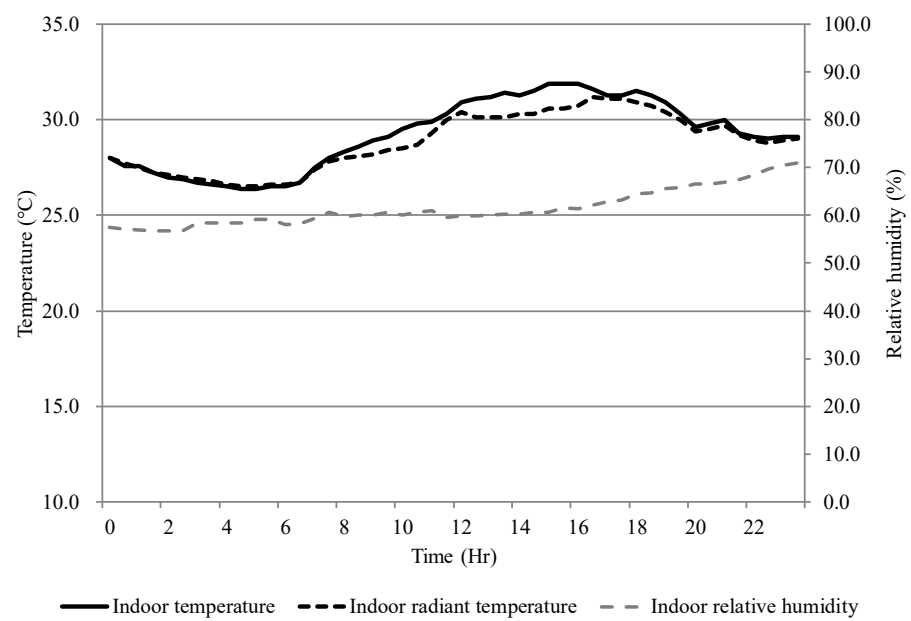

Fig. 9. Temperature and relative humidity in the cafeteria after improvement

\subsection{Measuring the indoor thermal environment of the personal living quarters}

At the home, every five living quarters comprise a group and share a common living room. The living room seldom used because the seniors stay within their own quarters most of the time. Every living quarter is $3.77 \mathrm{~m} \times 3.4 \mathrm{~m}$ with a floor area of $12.58 \mathrm{~m}^{3}$; there is also a bathroom in the suite with a floor area of $2.3 \mathrm{~m}^{3}$.

The following modifications were made to the space and equipment. Fans were installed inside the facility and connected to the heat pump and hot water system, with the activating temperature set at $28{ }^{\circ} \mathrm{C}$ and the output air temperature set at $27^{\circ} \mathrm{C}$. Window-type air conditioners were also installed, with the activating temperature set at $28{ }^{\circ} \mathrm{C}$ and the output air temperature set at $24{ }^{\circ} \mathrm{C}$. Circulation fans were added indoors and set to operate for 5 minutes every 2 hours. Ventilators were installed in the bathrooms and set to operate for 5 minutes every hour.

\subsubsection{Results from indoor thermal comfort measurements}

Measurement of the summer indoor temperatures and combined temperature thermal index (WBGT, wet-bulb globe temperature) showed that the temperature was maintained at $28.5-30.6{ }^{\circ} \mathrm{C}$ and that the combined temperature thermal index (WBGT) was maintained at $28.6-31.1^{\circ} \mathrm{C}$. These values are slightly higher than those in prior studies. Observation of the volunteer subjects' behaviors showed that they found the slightly higher indoor temperature to be acceptable and proactively turned off the window-type air conditioners. Compared with the study of Hwang R. L. et al. [13], which found the comfortable summer temperature for Taiwanese seniors to range between 23.2 and $27.1^{\circ} \mathrm{C}$, the actual measurements in this study were slightly higher, by $1.4-3.5^{\circ} \mathrm{C}$.

The humidity level affects the speed at which the body can dissipate heat, in turn affecting the feeling of comfort. At high temperatures, hot and humid air hinders sweat evaporation and increases the chance of heat stroke. Figs. 10 and 11 above show measurements of indoor relative humidity inside the personal living quarters during summertime, which stayed around 
70.4-88.5 \%. These values are 10-28.5\% higher than those of prior studies, which concluded that the most comfortable relative humidity was $40-60 \%$. The resulting more humid environment may be attributed to the home being located near the mountains. Observation of the relative humidity distribution showed that higher values usually occurred in the evening and at night, at 17:00-19:00 and 21:00-23:00, roughly after the volunteer subjects had showered, which caused a relatively more humid environment. The lower values usually occurred in the early morning, at 05:00-07:00.

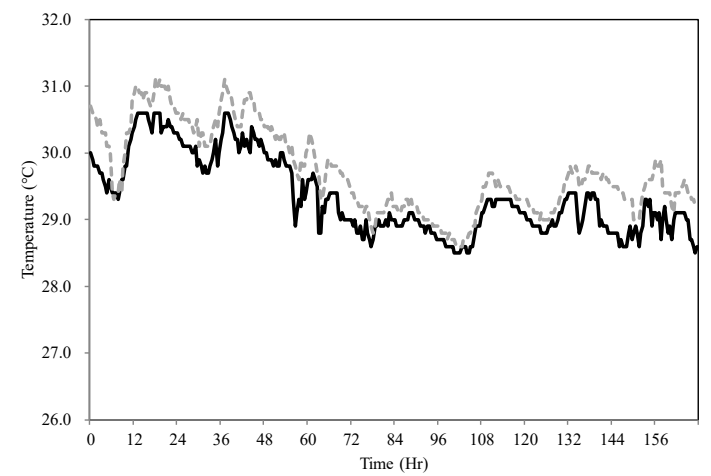

Fig. 10. Comparison between the indoor temperature and combined temperature thermal index over one week

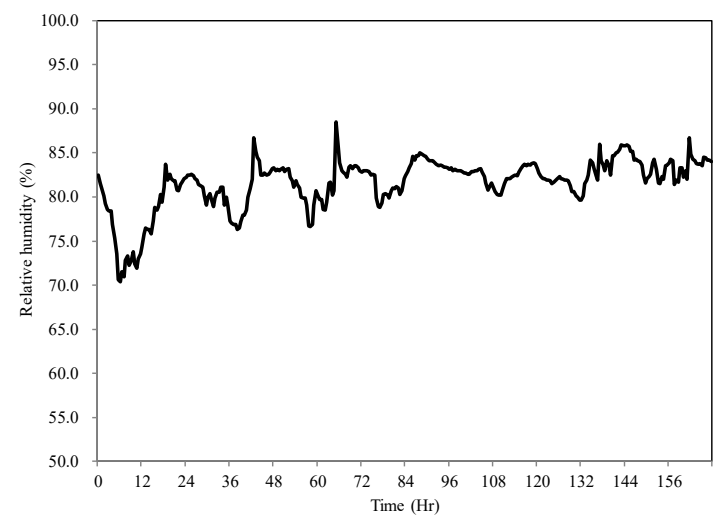

Fig. 11. Indoor relative humidity over one week

\subsubsection{Indoor thermal comfort (predicted mean vote, PMV and predicted percentage dissatisfied, PPD)}

The factors affecting the indoor thermal comfort indicator, PMV, include indoor environmental factors and human factors. The indoor environmental factors include dry ball temperature, relative humidity, black ball temperature (average radiant temperature) and wind velocity. The human factors include Metabolic Equivalent of Task (met) and thermal insulation by clothing (CLO). In the experiment, set values were given to the human factors according to the seniors' lifestyle. For Metabolic Equivalent of Task (MET), observation of the volunteer subjects in their living space indicated that they slept from 10:00 pm to 5:00 am the next day and napped between 12:00 pm and 2:00 pm (lunch time began at 11:30 am). During the rest of the time, they often sat still, watching TV and reading newspapers and magazines. Referencing ISO7730 requirements, the MET values were set at 0.8 during the sleeping hours and 1.0 for the rest of the day. The CLO values were set at 0.3 during the sleeping hours and 0.5 for the rest of the day. Fig. 12 shows indoor PMV measurements inside the personal living quarters in the summer; PMV 
was maintained at $0.12-2.17$, which may be classified as slightly warm to hot. Since MET and CLO were assigned different values based on the volunteer subjects' daily schedules, the PMV values were lower, 0.30-1.68, during sleeping hours because the MET and CLO values were also lower. Due to the greater amount of activity during the day, the MET and CLO values were higher, so the PMV values rose to 1.41-2.1. Fig. 13 illustrates the overall distribution of PMV values, with most of them falling into the ranges of $1.5-2.0$ and $1.0-1.5$, at $36.01 \%$ and $28.87 \%$, respectively. The lowest distribution was the 2.0-2.5 range at $8.04 \%$. Overall, the conditions were "warm" most of the time. Fig. 14 illustrates the distribution of PPD values, with the highest dissatisfaction rates falling into the $40-60 \%$ range for $40.77 \%$ of the time.

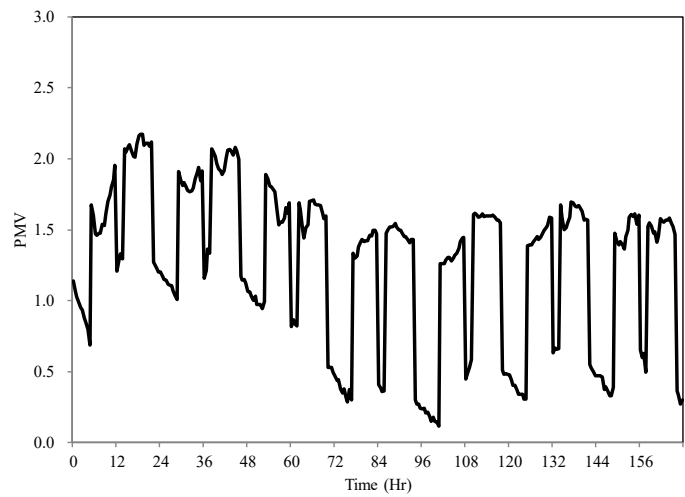

Fig. 12. PMV value measured over one week (summer)

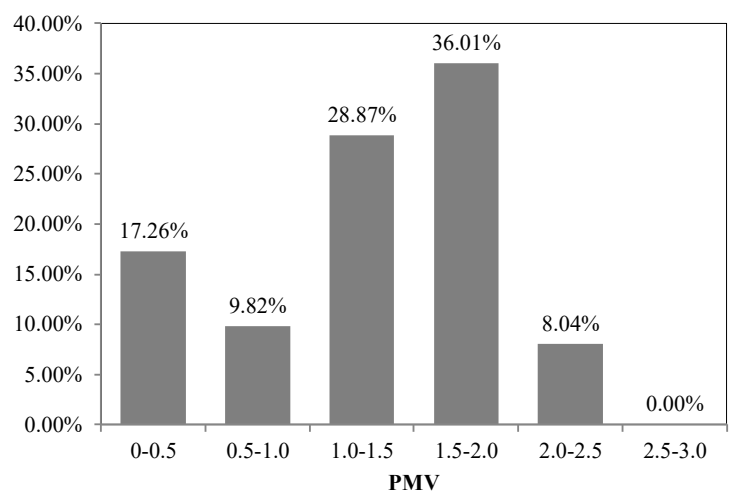

Fig. 13. Distribution of measured PMV values

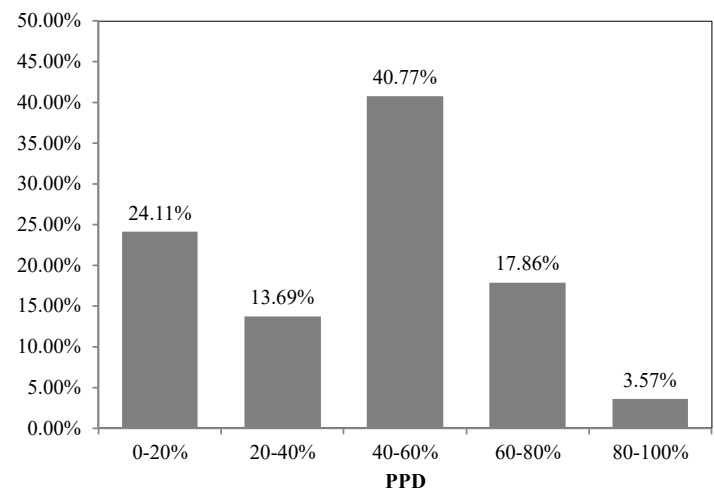

Fig. 14. Distribution of measured PPD values 


\section{Conclusions}

A new type of heat pump is proposed in this study. It combines the condenser of an air conditioning system and a heat pump. The heat pump system absorbs heat from the air and the heat emitted by the condenser. This heat is stored in the form of hot water, and the cold source after heat transfer is stored as cold water instead of being discharged into the atmosphere so as not to cause energy waste. Under different climate conditions, different services are provided-cooling in the summer and heating in the winter-creating a high-quality care environment and achieving energy efficiency at the same time. The study explored seniors' perceptions of environmental changes and thermal comfort in their living environment and how the heat pump system may be used to improve the indoor environment of a long-term care space for seniors, with a view to proposing ways to improve the indoor thermal environment. Conclusions may be drawn in the three following aspects:

1. Data collected over time during the test stage showed that a drop of $3{ }^{\circ} \mathrm{C}$ in temperature and a reduction to $55-65 \%$ in relative humidity are sufficient for comfort. Relative humidity of 40-60\% feels comfortable, with higher relative humidity feeling warmer. The results confirmed that the heat pump system can help improve the comfort of the indoor environment.

2. Test results of the indoor environment in the personal living spaces showed that the indoor temperature was maintained at $28.5-30.6{ }^{\circ} \mathrm{C}$ and that the combined temperature thermal index (WBGT) was $28.6-31.1^{\circ} \mathrm{C}$; this range is higher than the established comfortable summer temperature of $23.2-27.1{ }^{\circ} \mathrm{C}$ for Taiwanese seniors. The indoor relative humidity was maintained at around 70.4-88.5\%; this range is higher than the optimal relative humidity of $40-60 \%$, which is attributable to the home being located near the mountains. The indoor summer PMV was maintained at $0.12-2.17$, which is slightly warm to hot. The highest distribution occurred in the ranges of $1.5-2.0$ and $1.0-1.5$, at $36.01 \%$ and $28.87 \%$, respectively. The highest distribution of dissatisfaction (PPD) occurred in the $40-60 \%$ range, accounting for $40.77 \%$ of the time. The benefit of this proposed system is that in summer, it can significantly improve the indoor environment by reducing the indoor temperature by $3-5^{\circ} \mathrm{C}$ and the relative humidity by $11 \%$.

3 . With regard to the performance of the heat pump system, observation over one year showed the temperature of the inlet cold water to be $7-10{ }^{\circ} \mathrm{C}$ and that of the outlet hot water to be $42-54{ }^{\circ} \mathrm{C}$. With regard to energy efficiency, based on a $95 \%$ confidence interval, the average annual electricity consumption per day was $32.65 \mathrm{kWh} /$ day, which was $32.65 \%$ of the consumption before the improvement. This translates to a reduction of $67.35 \%$ and good improvement in energy efficiency using the system.

A long period of observation revealed that this proposed new heat pump system provides an energy saving effect, and when this system is installed in a public space, it can effectively improve the environmental comfort. However, when this system is installed in a living space, the environmental comfort can be improved, but the effect is limited by the form of the structure and space. Overall, this system has good energy-saving efficiency and practicality.

\section{References}

[1] Estimates by the National Development Council on the population in the Republic of China (Taiwan) between 2016 and 2061. Executive Yuan, Taiwan, R.O.C., 2016, https://www.ndc.gov.tw/Content_List.aspx?n=84223C65B6F94D72.

[2] Global Health and Aging. National Institute on Aging and National Institutes of Health, Department of Ageing and Life Course, World Health Organization, 2011.

[3] Definition of the Indicators of Population Ageing, World Population Ageing 1950-2050. Population Division, DESA, United Nations.

[4] Branch L. G. Health practices and incident disability among the elderly. American Journal of Public Health, Vol. 75, Issue 12, 1985, p. 1436-1439.

[5] Junker M. T., Koller C. M. An assessment of indoor air contaminants in buildings with recreational activity. The Science of Total Environment, Vol. 246, 2000, p. 139-152. 
[6] Mui K. W., Wong Fong L. T. K. N. K., Wong W. W. Y. Evaluation of indoor environment quality of elderly centers of Hong Kong. International Journal for Housing Science, Vol. 32, Issues 2, 2008, p. 121-131.

[7] Sterling E. M. Criteria for Human Exposure to Humidity in Occupied Building. ASHRAE Winter Meeting 1985.

[8] ASHRAE Handbook HVAC Applications, Chapter 8, Health Care Facilities, ASHRAE, 2011.

[9] Standard 62-1999, Ventilation for Acceptable Indoor Air Quality, ASHRAE, 1999.

[10] Thermal Comfort. ASHRAE handbook Fundamental, ASHRAE, 1997.

[11] Tashtoush B., Molhim M., Al-Rousan M. Dynamic model of an HVAC system for control analysis. Energy, Vol. 30, Issues 7-8, 2005, p. 1729-1745.

[12] Fanger P. O. Thermal Comfortable. ASHRAE Handbook of Fundamental, Chapter 8, 1997.

[13] Hwang R. L., Chen C. P. Field study on behaviors and adaptation of elderly people and their thermal comfort requirements in residential environments. Indoor Air, Vol. 20, Issue 3, 2010, p. 235-245.

[14] Toh K. C., Chan S. K. Thermo siphon heat recovery from an air-condition for a domestic hot water system. ASHRAE Transaction, Vol. 99, Issue 1, 1993, p. 4259-4264.

[15] Okamoto $S$. A heat pump system with a latent heat storage utilizing seawater installed in an aquarium, Energy and Buildings, Vol. 38, 2006, p. 121-128.

[16] Hu B., Xu Wang S. R. Z., Liu H., Han L., Zhang Z., Li H. Investigation on advanced heat pump systems with improved energy efficiency. Energy Conversion and Management, Vol. 192, 2019, p. 161-170.

[17] Shao S., Zhang H., You S., Zheng W., Jiang L. Thermal performance analysis of a new refrigerantheated radiator coupled with air-source heat pump heating system. Applied Energy, Vol. 247, 2019, p. 78-88.

[18] Pei J., Wang W., Pavesi G., Osman M. K., Meng F. Experimental investigation of the nonlinear pressure fluctuations in a residual heat removal pump. Annals of Nuclear Energy, Vol. 131, 2019, p. 63-79.

[19] Zhou C., Ni L., Li J., Lin Z., Wang J., Fu X., Yao Y. Air-source heat pump heating system with a new temperature and hydraulic-balance control strategy: a field experiment in a teaching building. Renewable Energy, Vol. 141, 2019, p. 148-161.

[20] Mastny P. Moravek J., Pitron J. Mathematical modeling of basic parts of heating systems with alternative power sources. Recent Advances in Fluid Mechanics and Thermal Engineering, 2015, p. $126-131$ 